Relations industrielles

Industrial Relations

\title{
Index 1949-1950
}

Volume 5, numéro 10, juillet 1950

URI : https://id.erudit.org/iderudit/1023415ar

DOI : https://doi.org/10.7202/1023415ar

Aller au sommaire du numéro

\section{Éditeur(s)}

Département des relations industrielles de l'Université Laval

ISSN

0034-379X (imprimé)

1703-8138 (numérique)

Découvrir la revue

Citer ce document

(1950). Index 1949-1950. Relations industrielles / Industrial Relations, 5(10),

101-101. https://doi.org/10.7202/1023415ar

Tous droits réservés (C Département des relations industrielles de l’Université Laval, 1950

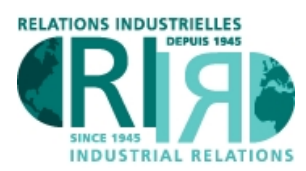

INDUSTRIAL RELATIONS
Ce document est protégé par la loi sur le droit d'auteur. L'utilisation des services d'Érudit (y compris la reproduction) est assujettie à sa politique d'utilisation que vous pouvez consulter en ligne.

https://apropos.erudit.org/fr/usagers/politique-dutilisation/
Cet article est diffusé et préservé par Érudit.

Érudit est un consortium interuniversitaire sans but lucratif composé de l'Université de Montréal, l'Université Laval et l'Université du Québec à

Montréal. Il a pour mission la promotion et la valorisation de la recherche.

https://www.erudit.org/fr/ 


\section{INDEX $1949-1950$}

Amélioration du langage de la profession (L') - Léonce Girard, No 9, juin, p. 81.

Application de la convention collective et administration du personnel - Fernand Jolicoeur, No 3, décembre, p. 30 .

Application de la Loi de la convention collective (L') No 4, janvier, p. 36.

Autorité dans l'entreprise (L') - Victor Morency, No 6, mars, p. 56.

Bilan des relations patronales-ouvrières (Un) - Roger Vézina, No 4, janvier, p. 33.

Capitalisme libéral et progrès social - Georges-Henri Lévesque, o.p., No 2, novembre, p. 14.

Caractéristiques concrètes du capitalisme libéral (Les) Georges-Henri Lévesque, o.p., No 5, février, p. 4I.

Cartels et l'arbitrage des prix (Les) - Maurice Lamontagne, No 7, avril, p. 63.

Cinquième année (Une) - La Rédaction, No 1, septembreoctobre, p. 1.

Cinquième congrès de l'A.P.I. (Le) - Gaston Cholette, No 3, décembre, p. 26.

Comportement des salaires dans l'industrie de l'imprimerie de Montréal et du district, 1940-1949 (Le) - Raymond Gaudreau, No 10, juillet, p. 95.

Congés annuels payés dans les conventions collectives du Québec - No 9, juin, p. 88.

Convention collective extensionnée nuit-elle à la petite industrie? (La) - Léonce Girard, No 10, juillet, p. 91.

Conventions collectives dans le Québec (Les) - No 8, mai, p. 79.

Date dans l'histoire de la pensée sociale catholique en cette province (Une grande) - La Rédaction, No 7, avril, p. 61 .

Définitions de la productivité - No 8, mai, p. 75.

Eglise catholique et les travailleurs (L') - S. Exc. Mgr Maurice Roy, No 1, septembre-octobre, p. 2.

Eglise et les problèmes économiques actuels (L') - No 2, novembre, p. 11.

Eglise dans la province de Québec est-elle opposée à l'établissement de capitaux étrangers? (L') — Gérard Dion, No 3, décembre, p. 21.

Embauchage (L') - Germain Giroux, No 1, septembreoctobre, p. 7.

Etablissement d'un fonds de pension peut-il faire l'objet d'une clause de convention collective? (L') - Ubald Désilets, No 8, mai, p. 72.

Formule Rand dans la décision arbitrale de l'amiante (La) - No 4, janvier, p. 38.

Importance actuelle de l'étude de l'entreprise - Gérard Dion, No 2, novembre, p. 12.
Industrie de la chaussure (L') - Gérard Tremblay, No 5, février, p. 43.

Initiative courageuse et réussie (Une) - Frère Justin, f.s.c., No 3, décembre, p. 25.

Jours fériés payés dans les conventions collectives de la province de Québec - No 10, juillet, p. 98

Jurisprudence du travail - Denys Dion, No 3, décembre, p. 28 - No 6, mars, p. 59 - No 7 , avril, p. $70-$ No 9 , juin, p. 87 - No 10 , juillet, p. 97 .

Liberté et sécurité syndicales - Jacques Archambault, No 6, mars, p. 55 .

Message de la responsabilité sociale (Le) - Vittorio Vaccari, No 3, décembre, p. 22.

Nature juridique et développement historique du droit du travail - René H. Mankiewicz, No 9, juin, p. 83.

Origine et essor du droit social: droit commun et droit de classe - René H. Mankiewicz, No 1, septembreactobre, p. 4.

Participation des travailleurs à la vie de l'entreprise (La) - Gaston Cholette, No 2, novembre, p. 17.

Réalisations professionnelles - Léonce Girard, No 8, mai, p. 73.

Réflexions sur le cinquième Congrès des relations industrielles - Gaston Cholette, No 8, mai, p. 71.

Réformes de structure dans l'entreprise - L. Perreault, No 2, novembre, p. 20.

Régime de sécurité sociale en Grande Bretagne? (Que vaut le) - Edgar Guay, No 5, février, p. 47.

Relations entre employeurs et employés dans les entreprises modernes - Jean Gagné, No 7, avril, p. 67.

Revues en relations industrielles (Les) - No 1, septembreoctobre, p. 10 - No 2 , novembre, p. $19-$ No 5 , février, p. 49.

Salaires et les prix (Les) - Maurice Lamontagne, No 6, mars, p. 52.

Sécurité sociale en Grande Bretagne (La) - Edgar Guay, No 4, janvier, p. 31.

Sens social à Toronto (Le) - Mgr Ferdinand Vandry, No 5, février, p. 49.

Statistiques et information - No 3, décembre, p. 28 No 5 , février, p. 50 - No 6, mars, p. 58 .

Structure des salaires - Gérard Tremblay, No 6, mars, p. 51 .

Syndicalisme catholique dans "Trade Unions in Canada" (Le) - Alfred Charpentier, No 2, novembre, p. 15.

Tribunaux du travail (Les) - Denys Dion, No 8, mai, p. 77. 